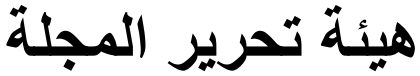

أ.د/ طارق فاروق عبد الصمد

رئيس مجلس إدارة المجلة

أ.د/ سيدة علي عبد العال

نائب رئيس مجلس إدارة المجلة

رئيس التحرير

أ.د// سامية فريد

نائب رئيس التحرير

أ.م د/ أحمد كمال رئبل التحيز

مدير التحرير

أ.د/ محمد قدري بكري

عضواً من خارج جهة الاصدار

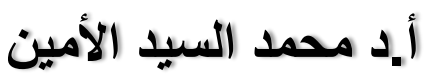

عضواً من خارج جهة الاصدار

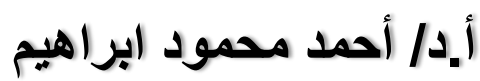

عضواً من خارج جهة الاصدار

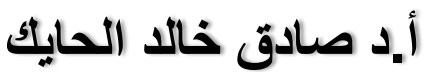

عضواً من خارج جهة الاصدار

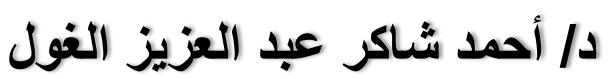

سكرتير تحرير المجلة 


\section{مستشاروا التحرير}

(مقررى وأمناء سر اللجان العلمية والأساتذة بالكلية)

- أ.د/أد/ مسعد سبيد عويس.

- أ.د/أبو العلا أحمد عبد الفتاح.

- أ.د// عبد المنعم السيد بدير.

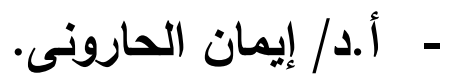

- أ.د/ أحمد عبد الخالق تمام.

- أ.د/ مدحت على أبو سريع. 


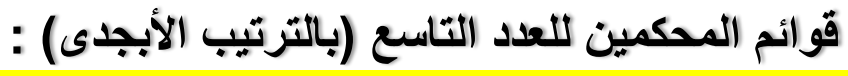

\begin{tabular}{|c|c|c|c|}
\hline جامعة حلوان الصــة الرياضـية كليـة التربيـة الرياضـية & & أ.د أحمد قدري & -1 \\
\hline ألريتاذ بقية جامعة الإديوة الرياضية و الترويح كلية التربية & & قأ.د/ أحمد عبد الحميد & $-r$ \\
\hline جامتة بنى سبو كرة اليد المتفرغ كلية التربية الرياضية & & أ.د/ أحمد عبد الخالق & $-r$ \\
\hline 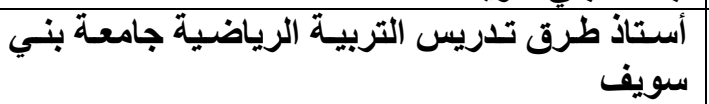 & & زا.دلو الثـــيماء ســــل & $-\varepsilon$ \\
\hline 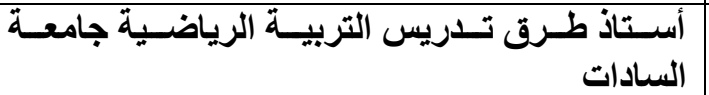 & & أ.د/ أميرة طه & -0 \\
\hline 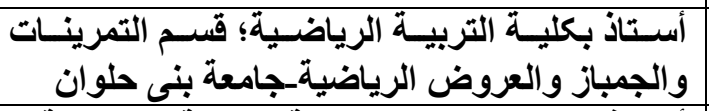 & & أ.د/ ايمان عبد العزيز & -7 \\
\hline 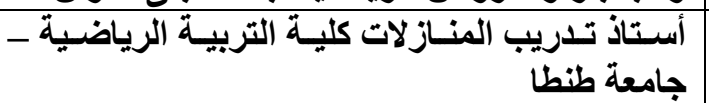 & : & البديوي & $-V$ \\
\hline جامعتة الاسكندرية النفس الرياضـي كلية التربيـة الرياضية & & أ.د/ با & $-\Lambda$ \\
\hline جامعة حلوان الصـة الرياضـية كليـة التربيـة الرياضـية & & أ.د/ حنان حسانين & -9 \\
\hline 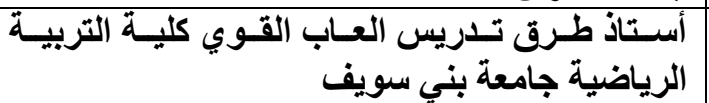 & & ا.د/ رانيا محمد سعيد & -1 \\
\hline جامعة حلوان النفس الَّياضسي كلية التربية الرياضية & & ا.ده/رة & -11 \\
\hline بني سويفت تلريب السباحة بكلية التربية الرياضية جامعة & & ا.داث/ رث & $-1 Y$ \\
\hline |الزقتازيق طرق التـريس كلية التربية الرياضية جامعة & & أ.د/ رشيد عامر & -14 \\
\hline 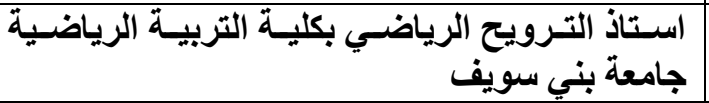 & $:$ & أ.دد/ سامية فريد & -1\{ \\
\hline بني سويفتاذ التعبير الحركي بكلية التربية الرياضية جامعة & : & ألعال/ سيدة علـي عبدا & -10 \\
\hline طنطاذ تدريب الملاكمة كلية التربية الرياضية جامعة & & أ.د/ شريف الجرواني & -17 \\
\hline 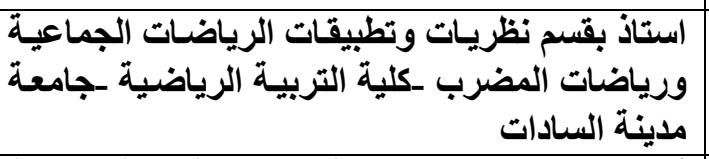 & & 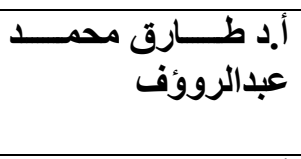 & $-1 V$ \\
\hline 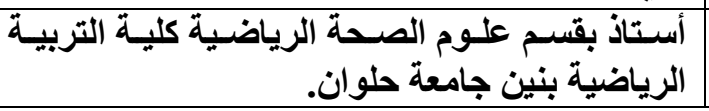 & : & أ.د/ عبد العزيز الملا & -11 \\
\hline
\end{tabular}


تابع قوائم المحكمين للعدد الثامن (بالترتيب الأبجدى) : التبادئ

\begin{tabular}{|c|c|c|c|}
\hline 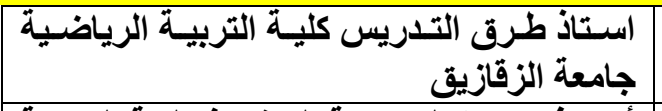 & & 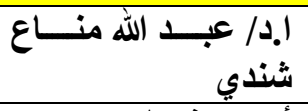 & \\
\hline 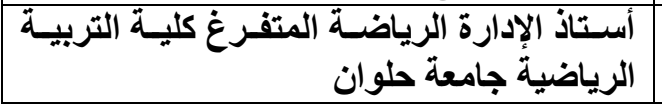 & & أ.د/ كوثر الموجي & $-r$ \\
\hline جامعة السادادة الرياضية بكلية التربية الرياضب & & أ.د/ لبيب : & r \\
\hline جامعة حلوان أصـول التربيـة كليـة التربيـة الرياضبـ & & 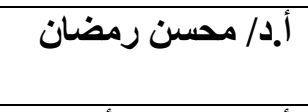 & r \\
\hline أستازيق طرق تـازيس التربيـة الرياضية جامع & & 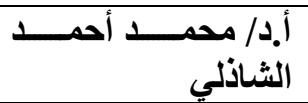 & $-r$ \\
\hline بني ستويف طبق تلدريس التربيـة الرياضية جامع & & سريع/ مـــلــت أبـــو & $-Y$ \\
\hline جامعة الاسكندرية المصارعه كلية التربية الرياضبّ & & أ.د / محمد الروبي & $-Y G$ \\
\hline أسوان طرق تـريس التربيـة الرياضية جامع & & 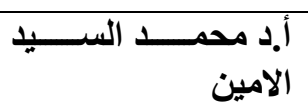 & ry \\
\hline جامعة بنـي سويف كرة السـلة كلية التربية الرياضب. & & أ.د/ محمود حسين & $-Y$ \\
\hline 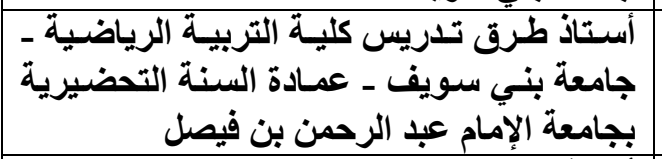 & & أ.دد/ مني عوض & $-{ }^{\prime} /$ \\
\hline جامعة طلوانم التعبير الحركي والجمباز المتفرغ & & 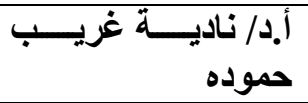 & $-T^{-}$ \\
\hline 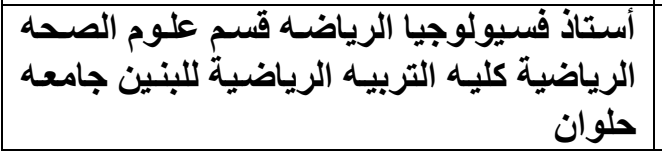 & & أ.د// نيفين فكري & $-r$ \\
\hline 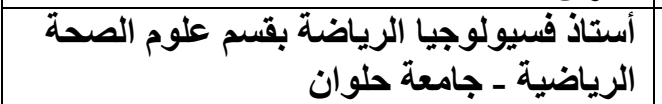 & & أ.د هيثم عبد & $-r$ \\
\hline أسرياضية جرق تلاريس جنوب العاب القوي كلية التربي & & أ.ـد هاني & $-r$ \\
\hline أستـاذ العـاب المضـرب كليـة التتربيـة الرياضِّ. & & أ.د/ & $-r T$ \\
\hline
\end{tabular}


هبلة بني سويف لعلوم التربية البدنية والرياضية - المبلد الخاهس

لائحة التشر لمجلة بنى سويف لعلوم التربية البلنية و الرياضية

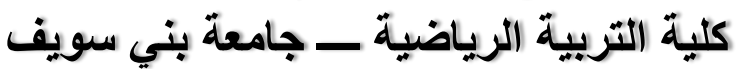

انطلاقاً من روئية ورسالة كلية التربية الرياضية بالاهتمام بالبحث العلمى والتميز فيه

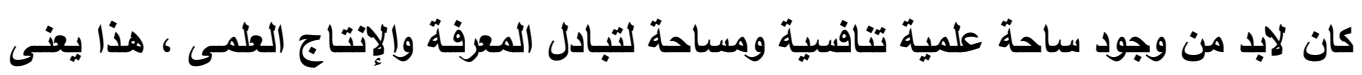

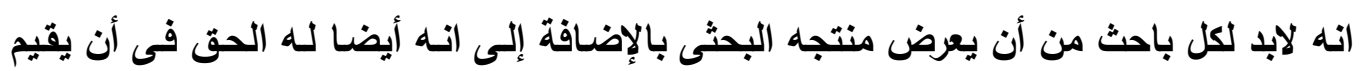
ويستفيد من أبحاث الآخرين.

ومن هنا تأتى أهمية المجلات العلمية فى المؤسسات التعليمية لذا فان كلية التربية

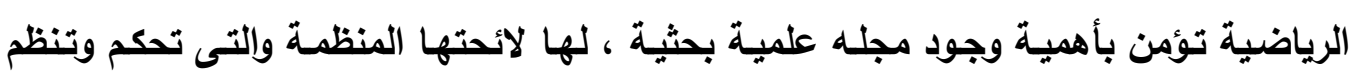
كافة أعمالها لتصبح مجله ذات قيمة علمية .

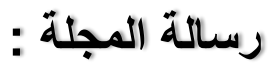

تختص المجلة بنشر الاراسـات والبحوث والمقالات العلمية فى المجـالات الرياضية

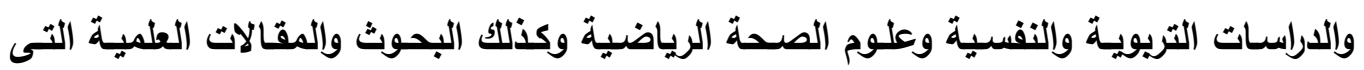
يجريها أو يشترك فى إجرائها أعضاء هيئة التريس ومعاونيهم والباحثين فى الجامعات ومراكز البهات

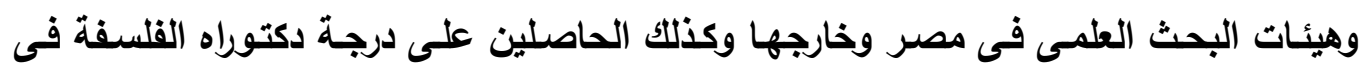

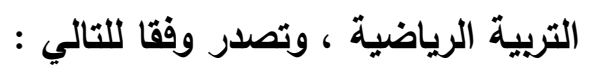
مادة (1) : (1) تصدر كلية التربية الرياضية بجامعة بنى سويف مجله علمية باسم - مجلة بنى

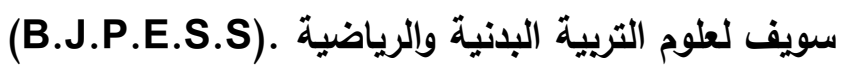
Beni-Suef Journal Of Physical Education And Sport

Sciences

مادة (r) : (r)

تصدر المجلة بصفة دورية نصف سنوية ( مارس - سبتمبر). 


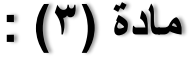

تثكل هيئة تحرير المجلة لمدة ثلاث سنوات بموافقة مجلس الكلية وذلك من السادة :

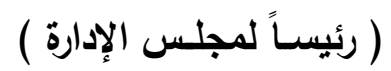

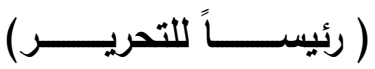

( نائبـاً لـرئيس التحريـر )

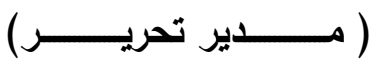

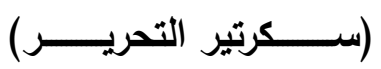

(أعضاء الهيئة الإستثارية)

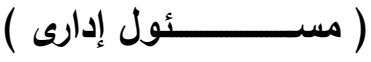

(مســـــــول مـــــــالى )
الأستاذ الاكتور عميد الكلية

الأستاذ الاكتور وكيل الكلية للاراسات العليا

عضو هيئة تدريس بالكلية

عضو هيئة تدريس بالكلية

عضو هيئة تدريس بالكلية

تسـعة مـن الســادة الأســاتذة أعضــاء هيئـة

التـريس بالكليـة ويجـوز أن يكونـوا مـن خـارج

الكلية للإستفادة من خبراتهم العلمية

أحد العاملين بالجهاز الادارى فى الكلية

أحد العاملين بالجهاز المالى بالكلية

ويتم إختيار السكرتير الإدارى بموجب قرار من ( رئيس مجلس الإدارة ) وياقتراح من

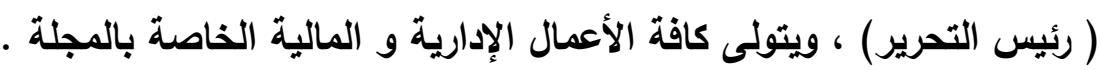

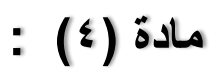

يتولى رئيس مجلس الإدارة تمثيل المجلـة أمسام الهيئات الأخرى وتصريف شئونها

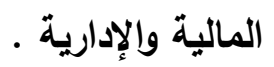




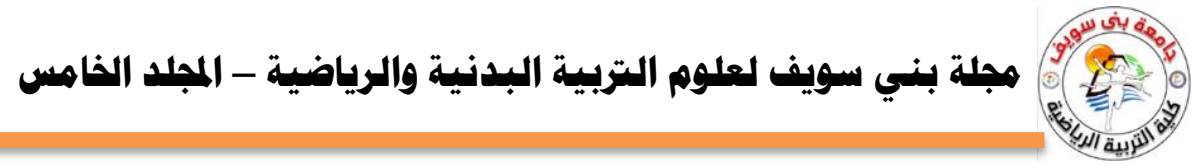

مادة (0) :

يقوم رئيس تحرير المجلة بالإشـراف على تلقى الأبحاث من الباحثين وتسجيل بياناتهم

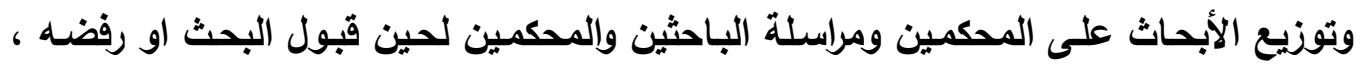

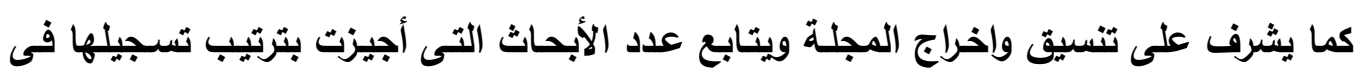

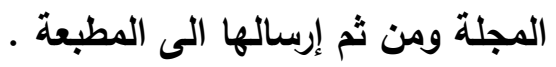

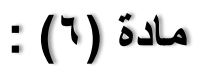
مدير التحرير مسئول عن متابعة كافة الإجراءات الخاصة باستلام البحوث وإعداد قواعد

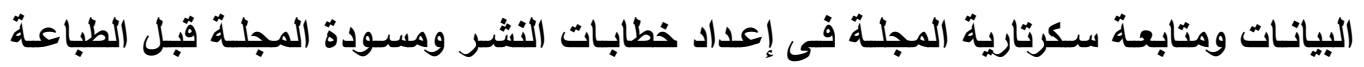

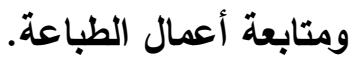

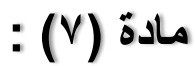

تنشـر الأبحـاث والمقـالات العلميـة التـى يجريهـا أو يشـترك فـ إجرائهـا أعضــاء هيئة

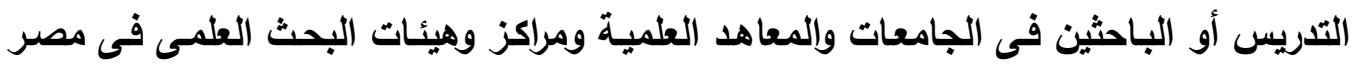
وخارجها . : مادة (1) البحث مسئولية الباحث ولا يجب أن يكون البحث قد قبل للنشر فى مجله علمية أو أى

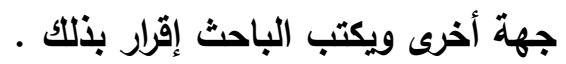

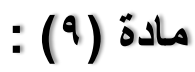
تنشر الأبحاث فى المجلة وفقاً لأسبقية ورودها بعد تحكيمها وإعدادها فى شكلها النهائى

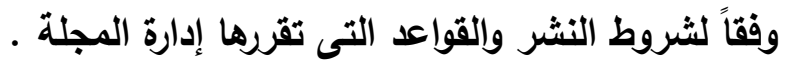

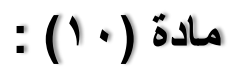
يتم ارسـال البحث عبر الموقع الرسمي للمجلة التابع لبنك المعرفه المصري ، ومن ثم يعرض البحث على رئيس التحرير ويعد مطابقته للقواعد الخاصة بالنشر بالمجلة يقوم بإرساله

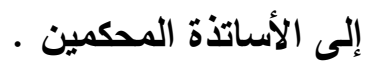

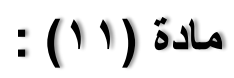

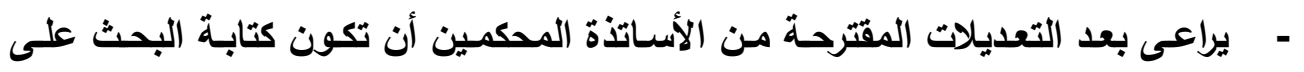

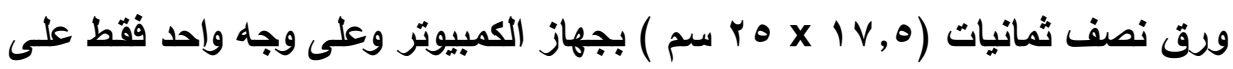


أن تترك ه, باسم من كل جوانب الورقة مع ترك مسافة بين الأسطر على أن يكون

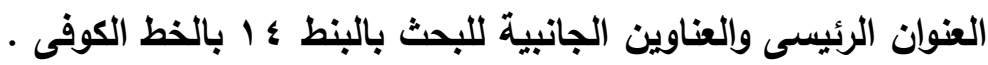

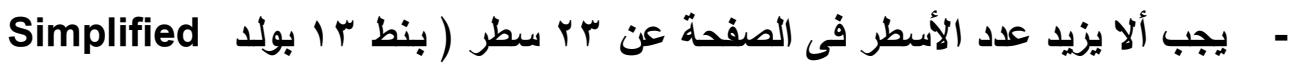

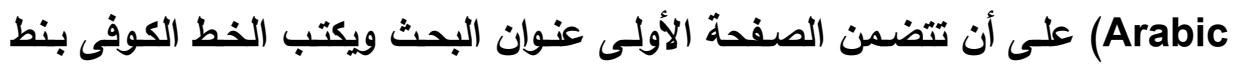

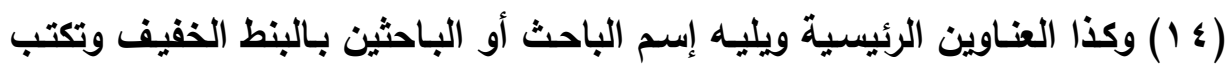
وظائف الباحثين أسفل الصفحة بالبنط . مادة (r)

تقبل البحوث بإحدى اللغتين العربية أو الإنجليزية .

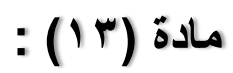

لا يجوز نشر البحوث العمية المنشورة بالمجلة بأى طريقة أو في أى مكان آخر إلا إلا

بإذن كتابي من رئيس مجلس الإدارة على أن يثار إلى العدد الذى ظهر فيه البحث لأول مرة .

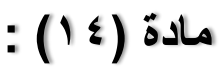

يقوم بتحكيم الأبحاث عدد (Y) من السادة الأساتذة ، الأول من أعضاء اللجان العان العلمية

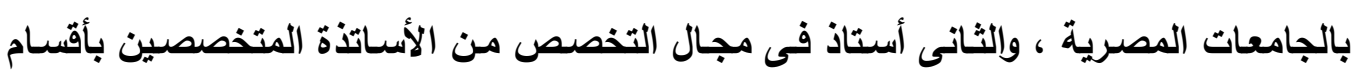

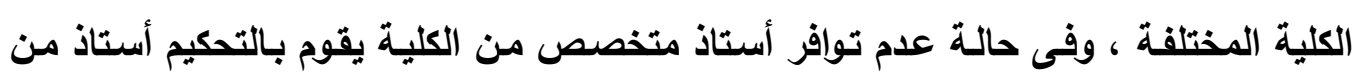

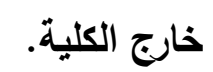
مادة (10) : مارجة بالنسبة للنشر العلمى للأساتذة من داخل الكلية يسمح لكل أستاذ بنشر بحث واحد فقط الكئ

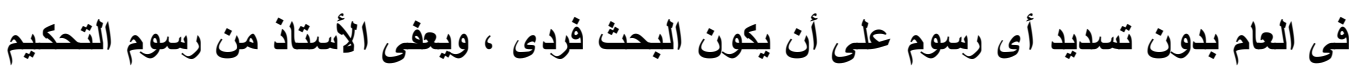

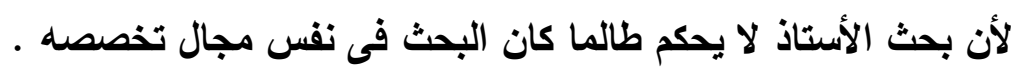

مادة (IV) : مع (iv)

يدعو رئيس مجلس إدارة المجلة أو من يفوضه إلى اجتماع لهيئة تحرير المجلة مرة كل ثلاثة أثهر بواقع أربعة مرات على الأقل خلال العام. 
هبلة بني سويف لعلوم التربية البدنية والرياضية - المبلد الخاهس

أحكام عامة : أشمات

ينشر البحث بالكامل كمـا قام المحكمون بتحكيمسه إلا فى حالـة عدم رغبة الباحث فى نشـر المرفقات . المات

يتم تطبيق أحكام القوانين واللوائح المعمول بها فى الجامعة فيما لم يرد نص بشأنه .

رئيس مجلس الإدارة

وعمبد الكية منية

أ.د/ طارق فاروق
نائب رئيس مجلس الإدارة

ووكيل الكلية للاراسات العليا مجلين

والبحوث

أ.د/ سيدة علي عبد العال 
هبلة بني سويف لعلوم التربية البدنية والرياضية - الجلد الخاهس

قائمة المحتويات

\begin{tabular}{|c|c|c|}
\hline رقم الصفحة & عنوان البمث وأسماء الباحثين & b \\
\hline$\varepsilon 9-1 \varepsilon$ & تأثير استفدام التعلم المعكوس على التصصيل المعرفي والأداء المهارى لمسابقة الوثب & \\
\hline$v r-0$. & تأثير دورة التملم الغماسي بإستفدام الهاسب الألي على التوافق الصركي & $r$ \\
\hline $1 . r-v \varepsilon$ & اليقظة الاستراتيجية ودورها في ثمقيق الميزة التنافسية بممامات السبامة & $r$ \\
\hline $\mid T T-1 . \varepsilon$ & 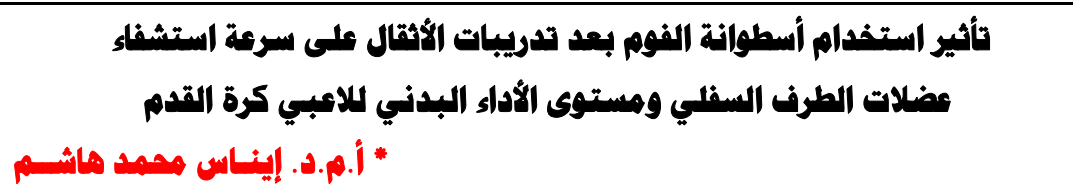 & $\varepsilon$ \\
\hline $170-1 \% \varepsilon$ & 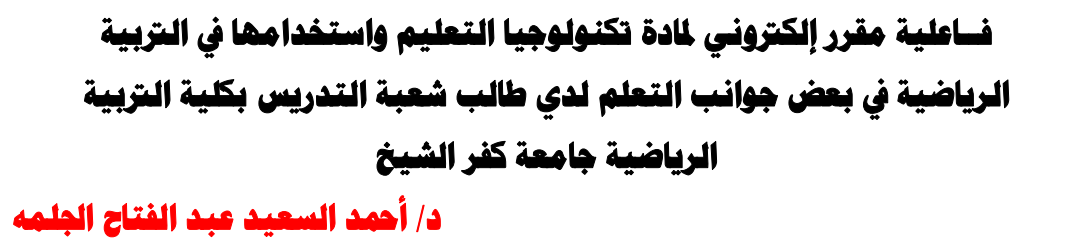 & -0 \\
\hline $14 V-177$ & 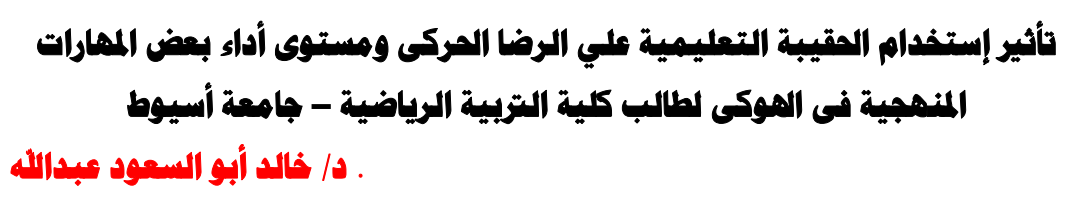 & -7 \\
\hline$r \cdot \lambda-1 M$ & 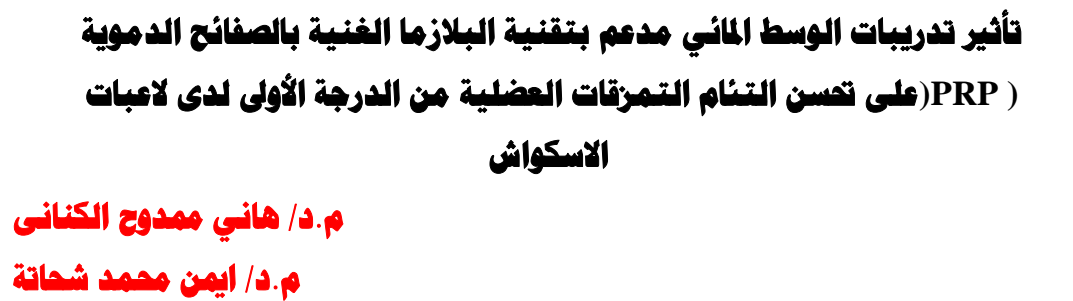 & $-r$ \\
\hline
\end{tabular}


هجلة بني سويف لعلوم التربية البدنية والرياضية - الجلد الخاهس

تابع المتويات

\begin{tabular}{|c|c|c|}
\hline رقم الصفهة & عنوان البمث وأسماء الباحثين & $p$ \\
\hline
\end{tabular}

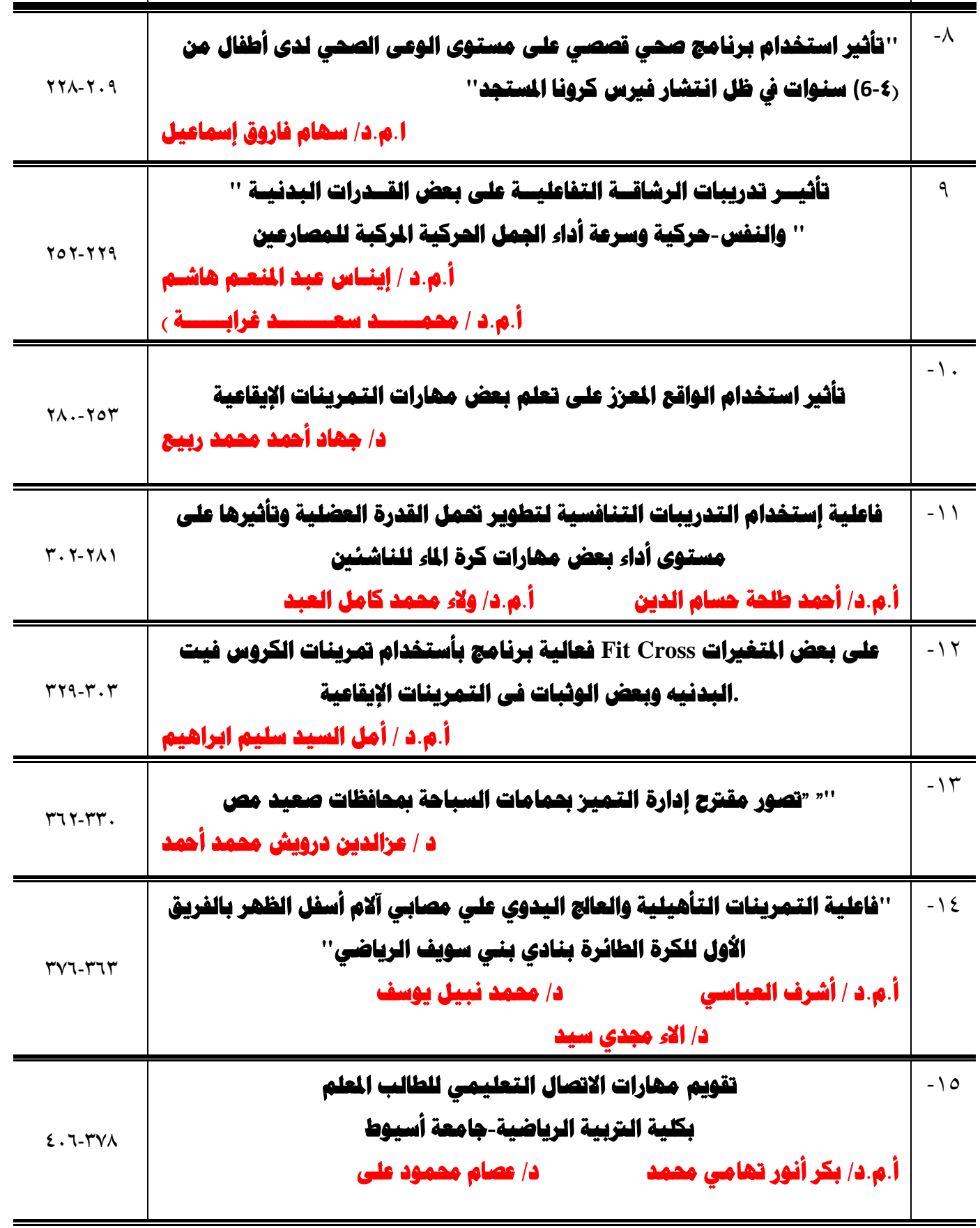


هجلة بني سويف لعلوم التربية البدنية والرياضية - المبلد الخاهس

\section{تابع المتويات}

\begin{tabular}{|c|c|c|}
\hline رقم الصفمة & عنوان البمث وأسماء الباحثين & $p$ \\
\hline$\varepsilon r \Lambda-\varepsilon \cdot \gamma$ & 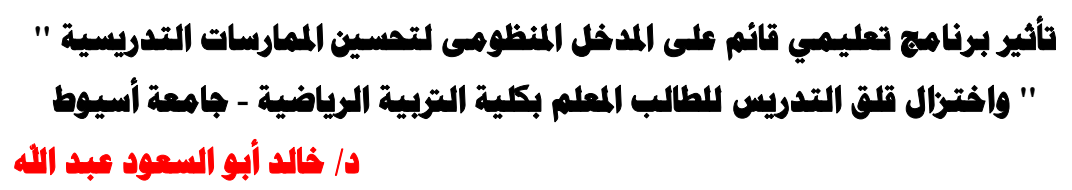 & -17 \\
\hline$\varepsilon 0 q-\varepsilon r q$ & 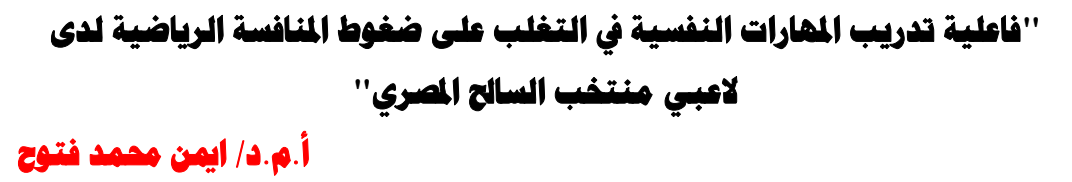 & $-I V$ \\
\hline$\{\wedge \varepsilon-\varepsilon\}$. & 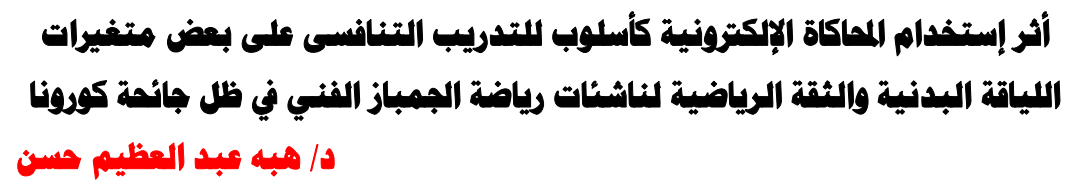 & -11 \\
\hline $01 .-\varepsilon \wedge 0$ & تأثير التدريبات التفصية على بعض المتغيرات البدنية وسرعة التشركات & -19 \\
\hline orl-oll & تأثير استفدام التدريبات المركبة على مستوى القدرة العضلية ومستوى الأداي & $-r$. \\
\hline OO1-OrY & تأثير استفدام تدريبات الرشاقة التفاعلية على بعض القدرات التوافقية ومستوي & $-r \mid$ \\
\hline OrT-oor & تصود مقترع لإنشاء نادى رياضى بكية تربية رياضية جامعة مدينة السادات & $-T^{2}$ \\
\hline $7.1 .0 V \varepsilon$ & آليات مشترحة لإدارة التميز كمدخل لتطوير مستوى الأداء الإدارى بمراكز التنمية & r \\
\hline TYY-T.Y & تأثير استفدام الكروس فيت على مستوى الكفاكة الوظيفية والأداء" & $-r \varepsilon$ \\
\hline
\end{tabular}

